\title{
Applied Talents Demand in Medical Research Related Engineering--Taking Shanghai as an Example
}

\author{
Zhu Dandan \\ Shanghai University of Medicine \& Health Sciences, Shanghai, 201318
}

Keywords: Vocational education; Medical related major; Applied talents training needs

\begin{abstract}
In Shanghai of 100 medical and health institutions at various levels and of medical related classes demand questionnaire investigation, around the job requirement, future demand and a new professional post demand questionnaire content such as design, Using spss17.0 software such as descriptive statistics, multiple response, chi-square analysis of statistical data, through questionnaire survey and interviews, to understand the need for a series of medical professionals related classes of the status quo, on this basis to improve medical related professional talent training system, improve the quality of medical professional talent training relating to and explore new professional to provide important basis to cultivate medical related classes.
\end{abstract}

\section{Introduction}

Promulgated by ministry of education of our country in 2001 the ministry of health, the China medical education reform and development compendium of medical education can be divided into medical education for the first time, the medical related class education ${ }^{[1]}$ 。 Integrated a number of policy and research, this article is mainly refers to the difference between medical related engineering in medical education, the training of clinical doctors in medical related professional education, vocational education, including nursing, pharmacy related and medical technology, health information, and other professional; It is both the universality of vocational education, but also has the particularity of medical education.

In this paper, all kinds of medical and health institutions at various levels in Shanghai medical related classes demand present situation research, and statistics analysis, found the problem, for medical related classes tuning of professional personnel training, the development of new specialty, the teaching quality of ascension and provides the basis for health personnel training plan formulation, etc, make the medical education relating to better serve the development of the region's health service and the people's growing health care needs, and form a leading role in the whole country.

\section{Data source and related instructions}

This research adopts the PPS sampling method to extract 10 administrative areas in Shanghai, extract four tertiary hospitals in each administrative area, three secondary hospitals and community health service center two and 1 biological medicine companies, a total of extract 100 institutions, Then the questionnaire survey to 100 institutions of the personnel management department, out 100 questionnaires, the actual recycling effective questionnaire 92, the recovery rate of $92.0 \%$, the tertiary hospitals 41 (44.6\%), 19 (20.7\%), second class hospitals, community health service center of 17 (18.5\%), medicine and health care companies eight (8.7\%), other institutions seven categories (7.5\%).And the survey of 100 institutions in accordance with the ratio of $10 \%$ of random sampling, extraction of 10 institutions (general hospital four, two secondary specialized subject hospital, community hospital and pharmaceutical companies enterprises 2) personnel interview, Interview object for the unit in charge of the dean (vp), personnel director, minister of human resources and department director (middle managers or technical backbone), etc., on the basis of literature study, two rounds of expert with the Delphi method is used for the design of the questionnaire and revision, 
the method of multistage PPS sampling different types and levels of the organization unit to a random sample. Raw data using Epidata 3.0 database entry, using spss17.0 software such as descriptive statistics, multiple response, chi-square analysis and processing. $\mathrm{P}<0.05$ for the difference is statistically significant.

\section{Demand Investigation of Medical professionals related classes}

Unit of choose and employ persons in medical related specialized student recruitment requirements, qualifications, abilities and certificate requirements are three basic elements.

From the employing units to its requirements for academic qualifications, in addition to health care requirements with tertiary education outside the majority (81.9\%), pharmaceutical and related classes and medical and health information such classes are requested to bachelor degree, the highest percentage $50.6 \%$ 61.9\% respectively, and 65.0\%.The employing units to medicine in the related class students to undertake recruitment and hiring, the main factors to be considered the top three are "employ predominantly undergraduate, tertiary students as a supplement." (59.5\%); the recruitment as required special secondary school, and college or undergraduates" (41.8\%); the colleges is too low (25.3\% not hire").

Unit of choose and employ persons is the essence of value most, of the top five were "professional skills" (84.0\%), "communication skills" (79.0\%), "professional knowledge" (58.0\%), and "learning" (35.8\%) and "easy-going personality, affinity" (30.9\%)."Professional skills" and "basic specialized knowledge is always a" unit of choose and employ persons relating to enroll medical professionals develop; At the same time, unit of choose and employ persons also agree that "communication ability" and "easy-going personality, affinity" is to serve the health posts relating to medical professionals necessary for soft power.

Seen from certificate requirement when recruiting sort results, the top three, respectively is "post vocational qualification certificate" (81.5\%), "the university English four levels (38.3\%)," "computer class" (32.1\%).

(Unit of choose and employ persons to hire graduates relating to medical satisfaction mainly from the following three indicators to investigate:1)Post operation skills of satisfaction: unit of choose and employ persons to employ different levels of medical graduates post operation skills are related to "satisfactory" accounts for the highest proportion, secondary specialized school students' respectively $56.7 \%, 77.8 \%$ college students, undergraduate students is $82.8 \%$.Overall, unit of choose and employ persons in the operating skills, to the satisfaction of junior college and undergraduate respectively: 93.7\%, 94.8\%, significantly higher than $63.3 \%$ of secondary specialized school students'. (2) Professional quality satisfaction data show that unit of choose and employ persons to employ different levels of medical graduates professional quality to "satisfactory" accounts for the highest proportion, secondary specialized school students' respectively $67.6 \%, 83.9 \%$ college students, undergraduates in $89.7 \%$.In general, unit of choose and employ persons in terms of professionalism, to the satisfaction of junior college and undergraduate respectively: $93.6 \%$, 98.2\%, significantly higher than the same $73.4 \%$ of secondary specialized school students'.

Unit of choose and employ persons the future professional recruitment by the largest number of the top three, respectively is "care" (64.4\%), "medical imaging technology" (33.8\%), "medical test technology" (22.2\%).Nursing profession requires college education occupies the highest proportion (51.3\%), interview also suggests that unit of choose and employ persons in nursing college degree more recognition, the other two professional requirement of the degree are given priority to with "the bachelor", accounted for $60.6 \%$ and $60.6 \%$ respectively. College professional meet demand from the unit of choose and employ persons, can be competent for the current and future demand for five years of professional top five is "care" (85.1\%), respectively, "medicine" (48.6\%), "medical imaging technology" (39.2\%);

From the unit of choose and employ persons to professional technical secondary school meet demand conditions, can be competent for the current and future demand for five years of 
professional of the top five were "are not up to (60.9\%)," "care" (23.9\%), "medicine" (8.7\%), "Chinese medicine" (4.3\%),Most of unit of choose and employ persons think the current level of technical secondary school and in the future five years medical related classes are not qualified for professional post job requirements, while nursing exception, there are still some unit of choose and employ persons think level of technical secondary school nursing talents can meet the requirements of this unit the position:After in-depth data analysis found that level of technical secondary school of nursing talents to meet the demand of this unit the position in the medical and health institutions, community health service center, the largest proportion of 54.5\%, secondary hospital and tertiary hospital accounted for $36.4 \%$ and $9.1 \%$, respectively.

Now some medical related engineering has been listed in the department of education has 18 professional directory, but Shanghai is not open, these are: professional health inspection and quarantine technology, respiratory therapy, medicine, biological technology, public health management and medical secretary. According to the survey, according to the current Shanghai medical and health undertakings development needs, is considered by research unit should be opened in Shanghai medical related engineering are: Rank respectively before and after "medical secretary" (41.4\%), "public health management" (27.1\%), "breathing treatment technology" (22.9\%), "' medical biotechnology (21.4\%)," health inspection and quarantine technology "(15.7\%).

With the development of medical industry and society to the growing demand for medical service, medical professional related classes derived some new positions, these jobs are:Medical social workers, logistics management (hospital), respiratory therapists, and psychological counselor/therapist and hospital accounting, etc.

In the investigation at present a new set of the new jobs of unit of choose and employ persons, ranking respectively before and after "hospital accounting" (79.6\%), "the hospital logistics management" (63.0\%), "medical social workers (53.7\%)," "psychological counselor/therapist" (25.9\%), respiratory therapists' (9.3\%).In the investigation of unit of choose and employ persons is not set and consider setting up jobs, ranked respectively before and after "the hospital logistics management" (45.8\%), "medical social workers (41.7\%)," "psychological counselor/therapist" (41.7\%), respiratory therapists' (33.3\%), and "hospital accounting" (20.8\%).

Way for the new derivative positions also has carried on the investigation, the results show that the medical social work and the hospital logistics management tend to "internal personnel training transfer or part-time (46.0\% and 39.2\%, respectively).Respiratory therapists and psychological counselor/therapist tend to "set up corresponding post new professional" (53.7\% and 36.4\%, respectively), the hospital accounting tend to "recruiting graduates similar training" (48.8\%).

\section{Research Conclusions and Policy Recommendations}

Facing the new situation of medical and health undertakings development, especially the new task, we will deepen reform of the medical and health system and the new characteristics of international competition for talent, combined with the survey data, Shanghai in medical related professional talents both in quantity and quality all showed a trend of increase in demand, on the basis of investigation and analysis of this research put forward the following Suggestions:

The survey shows that in addition to the nursing, pharmacy and related classes, medical and health information requirements is given priority to with bachelor's degree, don't even consider technical school education. Through further study of the relationship between the degree requirements and hospital level after found that tertiary hospitals tend to hire more bachelor degree and above levels of the various types of professional graduates, and the level of technical secondary school the class personnel shall not be considered; Secondary and community health centers tend to bachelor of medicine and health information, junior college of nursing, medical professional, technical secondary school level talent part needs. Therefore suggested: first, build a multi-level, multi-type medical related professional education system, well versed in medicine undergraduate and graduate student talent cultivation system related classes, not only ensure the medical related 
classes of higher education development and sustainable development as a whole.Second, in medical Settings and related engineering construction should not only to meet the needs of the lateral dynamic, according to the market demand, regional economic development needs, industry development needs of dynamic management, excellent into worse tide; To adapt to the longitudinal hierarchy of needs, timely improve personnel training level.

This study also understands in the interview process, the current cultivating professional talents of some medical related classes of insufficient demand, and this problem more prominent major is health information management. Medical related classes to give an accurate localization of professional development, adapt to the needs of society and medical science and technology development trend. First, to carry out the professional research and optimize the talent training mode. Through investigation and research, timely understanding of professional post demand, the corresponding industry explore depth fusion method with industry development and innovation personnel training mode, dynamic optimization of the talent training scheme, realize the seamless joint between talent training and position requirements. Second, deepening the reform of course system, explore to cultivate innovation spirit and practice ability as the key course system. Third, pay attention to the cultivation of professional quality, improve the ability of communication.

Research found that medical and health unit to the medical social work, medicine, secretarial, hospital logistics management, psychological consultants, and other traditional medicine in relevant professional derived class professional direction must know and demand."The emergence of new derivative positions and, it will be affect the quality of hospital services, medical technology level, etc., and even become a social effect hospital, one of the key factors for sustainable development, become the important supplement of the biomedical model". ${ }^{[3]}$ The author suggested: first, the related colleges and universities should be innovative concept, in a timely manner to capture the market due to the demand of emerging jobs derived medical related major. Medical social workers, for example, such as the introduction of the new professional direction and development are the current of "biology - psychology - social medical model. They have to help patients to enjoy medical treatment unit of medical resources, provide treatment knowledge and psychological counseling and guidance, integration of all kinds of resources related to patient care, help people overcome difficulties and solve various contradictions in the process of medical treatment, promote the doctor-patient communication, help to improve the doctor-patient relationship, etc. Second, the relevant departments to build platform, provide policy support."The emergence of new derivative positions and, it will be affect the quality of hospital services, medical technology level, etc., and even become a social effect hospital, one of the key factors for sustainable development, become the important supplement of the biomedical model." ${ }^{[2]}$ This as soon as possible on the one hand for health policy makers to harmonise the professional occupational qualification admittance standard or system, to carry out the supporting system, for medical related classes give specification and guide the new professional Settings; On the other hand, the establishment of the corresponding title series, through responsibility. it pathway, safeguard the professional development. In addition, also need to participate in the whole society, joint effort, attention and focus on the professional development, given the larger development space.

\section{References}

[1] Medical science [2001]212, outline of Chinese medical education reform and development [s]

[2] Luo Lei, Ji Fang, Chai Shuang: military hospital management: a new concept of medical social work research and development [j]. The PLA hospital management magazine, 2014 (08): 705-706. 